\title{
Energy harvesting from pavement via polyvinylidene fluoride: hybrid piezo-pyroelectric effects"
}

\author{
Junliang $\mathrm{TAO}^{\dagger}$, Jie $\mathrm{HU}$ \\ (Department of Civil Engineering, The University of Akron, ASEC 210, Akron, OH 44325-3905, USA) \\ †E-mail: jtao2@uakron.edu
}

Received Feb. 18, 2016; Revision accepted Apr. 19, 2016; Crosschecked June 25, 2016

\begin{abstract}
In the USA, there are over 4 million miles (6 million $\mathrm{km}$ ) of roadways and more than 250 million registered vehicles. Energy lost in the pavement system due to traffic-induced vibration and deformation is enormous. If effectively harvested, such energy can serve as an alternative sustainable energy source that can be easily integrated into the transportation system. It is well known that most piezoelectric materials are also pyroelectric materials, which convert temperature change into electricity. However, the potential of polyvinylidene fluoride (PVDF) as a hybrid piezo-pyroelectric energy harvester has been seldom studied. The uniqueness of this study lies in that the electrical responses of PVDF under coupled mechanical and thermal stimulations are investigated. Through a series of well controlled experiments, it is found that there exists an interesting coupling phenomenon between piezoelectric and pyroelectric effects of PVDF: the voltage generated by simultaneous mechanical and thermal stimulations is the algebraic sum of voltages generated by separate stimulations. This means that there is neither strengthening nor weakening coupling effect when the piezoelectric and pyroelectric phenomena are coupled. This also makes the modeling process of the hybrid piezoelectric and pyroelectric effect straightforward. An estimation of power generation through piezoelectric and pyroelectric effect is conducted, and the overall effects of temperature on hybrid piezo-pyroelectric energy harvesting are discussed.
\end{abstract}

Key words: Energy harvesting, Pavement, Piezoelectric, Pyroelectric, Hybrid http://dx.doi.org/10.1631/jzus.A1600166

CLC number: U41; TK01

\section{Introduction}

Fossil energy sources such as coal, natural gas, and petroleum have been mainly used in countries as they become developed. However, because of excessive consumption, those energy sources will become depleted in the future, and sustainable energy is an ideal replacement. Traditional sustainable energy sources such as wind energy, solar energy, geothermal energy, and hydraulic energy have been developed for decades or even thousands of years. However, these forms of energy are greatly subjected to

\footnotetext{
* Project supported by the College of Engineering, and the Biomimicry Research and Innovation Center at the University of Akron (No. UA 1000002424), USA

(DD ORCID: Junliang TAO, http://orcid.org/0000-0002-3772-3099

(c) Zhejiang University and Springer-Verlag Berlin Heidelberg 2016
}

weather and location. A novel sustainable energy harvested from pavement systems is proposed in this study. By embedding energy harvesters in the pavement structure, electricity can be generated when vehicles pass by. The concept of piezoelectric energy harvesting from a pavement system exhibits great potential, as indicated by a recent investigation conducted by the California Energy Commission: less than two miles of pavement implemented with piezoelectric energy harvesters can supply enough energy to power a typical home (Hill et al., 2014). While promising, this concept is still in its infancy due to various challenges in system design, materials, modeling, and implementation.

In the proposed energy harvester system, a piezoelectric material is utilized that is able to convert mechanical deformation into electricity. Piezoelectricity was discovered in 1880 by Jacques Curie and 
Pierre Curie (Ueberschlag, 2001). Piezoelectric materials can be found in nature, such as in quartz and animal bones. Synthesized piezoelectric materials, such as lead zirconate titanate (PZT) and polyvinylidene fluoride (PVDF), are more commonly used for engineering applications. PZT is an inorganic ceramic material and is fragile in nature, although it has a large piezoelectric coefficient. On the other hand, PVDF is a flexible and durable polymer material with a much smaller piezoelectric coefficient. As a pilot study, Virginia Tech proposed a pavement energy harvesting system consisting of a metal box and stacks of PZT discs (Xiong et al., 2012). The design is thought to be bulky and would adversely affect the pavement system due to a mechanical mismatch between the pavement and the metals. The durability of the system was found to be questionable due to the fragile nature of the ceramics. Furthermore, the potential pyroelectric effect is not considered. Zhao et al. (2010) proposed a cymbal-shaped PZT-based energy harvester and analyzed its coupling with asphalt pavement structure using a finite element model. PVDF-based energy harvesters have also been investigated that convert ambient vibration into electricity (Chen, 2014). However, the energy efficiency of a piezoelectric energy harvester is fairly low, which limits its broad application.

To combine the merits of inorganic and polymeric piezoelectric materials, hybrid materials have been developed in the recent years. Thomas et al. found that the additive of $\mathrm{CaCu}_{3} \mathrm{Ti}_{4} \mathrm{O}_{12}$ (CCTO) in PVDF increases the dielectric constant to 95 (Thomas et al., 2010). Guan et al. (2013) discovered that PZT/PVDF doped with carbon nanotubes gradually increase the piezoelectric constant $\left(d_{33}\right)$ with small volume fractions. However, when the volume fraction of carbon nanotubes approximates to $1 \%$, $d_{33}$ decreases. Luo et al. (2014) presented the relationship between volume fractions of calcium barium zirconate titanate $\left(\mathrm{Ba}_{0.95} \mathrm{Ca}_{0.05} \mathrm{Zr}_{0.15} \mathrm{Ti}_{0.85} \mathrm{O}_{3}\right.$, $\mathrm{BCZT}$ ) and dielectric constant. They found the dielectric constant increases with the addition of BCZT. Huang et al. (2014) demonstrated that the loading of graphene oxide changes the properties of PVDF and that $0.1 \%$ (weight fraction) of reduced graphene oxide (rGO) increases the piezoelectric constant by 78.6\%. However, Rahman and Chung (2013) added $0.3 \%$ (weight fraction) of rGO in PVDF, and it was reported to increase the dielectric constant by $320 \%$. Zhang et al. (2001) synthesized $\mathrm{Pb}\left(\mathrm{Mg}_{1 / 3} \mathrm{Nb}_{2 / 3}\right) \mathrm{O}_{3}$ $\mathrm{PbTiO}_{3}$ (PMN-PT), and they found PMN-PT to exhibit a very high value for the piezoelectric coefficient. Appropriate addition of multi-walled carbon nanotubes (MWCNTs) in PVDF increases the piezoelectric constant. However, extensive use of MWCNTs can reduce $d_{33}$ (Kim et al., 2009).

It is also well known that most piezoelectric materials are pyroelectric materials, which convert temperature change into electricity. The pyroelectric properties of PZT/PVDF composites have been recently investigated. Dietze and Es-Souni (2008) added PZT to poly[(vinylidenefluoride-co-trifluoroethylene] (PVDF-TrFE) to produce a PZT-PVDF-TrFE composite. This increased both the dielectric constant and the pyroelectric constant. However, the high PZT content was reported to decrease the dielectric constant and pyroelectric constant. The PZT contained in the PZT/PVDF-HFP composite contributed to both its pyroelectric and piezoelectric constants. Under high temperature conditions, the pyroelectric constant of PZT/PVDF-HFP composite was reported to increase greatly (Malmonge et al., 2003). However, the potential of using PVDF composites as a hybrid piezo-pyroelectric energy harvester has seldom been studied.

The ultimate goal of the present study is to develop a highly efficient pavement energy harvesting system utilizing the hybrid piezo-pyroelectric effect of PVDF composites. As the first step, this paper discusses the effects of temperature variation on the power generation using pure PVDF samples. The temperature effects are often neglected in most of the previous studies but they may have significant influence on the modeling of the energy harvesting system. This is because temperature not only influences the piezoelectric effect, it may also induce pyroelectric charges when the temperature changes. A series of experiments on electricity generation from the pure piezoelectric effect, pure pyroelectric effect, and hybrid piezo-pyroelectric effect are conducted. Based on the test results, theoretical models are developed to predict the power generation through the hybrid piezo-pyroelectric energy harvesting system. A case study is presented to illustrate the effects of temperature variation on energy harvesting from pavement. 


\section{Piezoelectric and pyroelectric effect of PVDF}

PVDF is selected as an energy harvesting material due to its excellent flexibility, chemical resistance, thermal stability and good mechanical properties. PVDF usually has amorphous microstructures and crystalline structures with polar and non-polar phases. The $\beta$ phase conformations of PVDF result in net non-zero dipole moments and thus demonstrate piezoelectric and pyroelectric effects. To achieve the desirable content of polar crystalline $\beta$ phase, it is typically necessary for the PVDF to be polarized under mechanical or electrical fields.

PVDF is a piezoelectric material, since the mechanical stress/deformation of the material will change the directions of the electric dipoles with a net effect of accumulating charges on the surface electrodes. The direct piezoelectric effect can be described as

$$
D=\varepsilon^{\sigma} E+d \sigma,
$$

where $\sigma$ is the mechanical stress, $D$ and $E$ are the electric displacement and electric field, respectively, $\varepsilon^{\sigma}$ is the dielectric permittivity in a constant stress status, and $d$ is the piezoelectric coefficient. Eq. (1) considers the full coupling effect between the mechanical and electrical fields. When the inverse piezoelectric effect and the effect of the generated electric field $(E)$ are neglected, the second expression in Eq. (1) can be simplified to Eq. (2), which can be utilized to calculate the charges (integration of $D$ on electrode areas) induced by the stress field $(\sigma)$ :

$$
D=d \sigma .
$$

PVDF is also a pyroelectric material that exhibits a spontaneous polarization $\left(P_{\mathrm{s}}\right)$ in the absence of an applied electric field. Pyroelectric materials produce electricity from temperature fluctuations $(\mathrm{d} T / \mathrm{d} t)$ and are analogous to piezoelectric harvesters, which convert mechanical oscillations $(\mathrm{d} \sigma / \mathrm{d} t)$ to electric energy. Eq. (3) defines the generated pyroelectric current $\left(I_{\mathrm{p}}\right)$ under temperature change $(\mathrm{d} T / \mathrm{d} t)$ :

$$
I_{\mathrm{p}}=\frac{\mathrm{d} Q_{\mathrm{T}}}{\mathrm{d} t}=\rho A \frac{\mathrm{d} T}{\mathrm{~d} t},
$$

where $Q_{\mathrm{T}}$ is the pyroelectric charge, $A$ is the surface area of the material, and $\rho$ is the pyroelectric coefficient.

Note that the mechanical and thermal boundary conditions for the PVDF films will affect its pyroelectric coefficients ( $\mathrm{Li}$ et al., 2013; Bowen et al., 2014): the primary pyroelectric effect is mostly relevant to the condition that the film is perfectly clamped and under constant strain with uniform heat distributions; if the film is not clamped and free to deform with temperature change, the secondary pyroelectric effect is present since thermal expansion/ contraction induces strain that alters the polarization via piezoelectric effect; if the film is under special temperature gradient, the tertiary pyroelectric effect is present since the gradient will result in shear stress which can also alter the polarization. Therefore, it is important to establish appropriate mechanical and thermal boundary conditions when studying the hybrid piezo-pyroelectric effect.

For pavement energy harvesting applications, the harvester will be subject to both mechanical stimuli (i.e., traffic-induced deformation and vibrations), as well as thermal stimuli (i.e., transient temperature changes). Therefore, it is interesting to study the coupled piezoelectric and pyroelectric effects and investigate how the temperature changes affect the piezoelectric effects as well.

\section{Laboratory experiments on the piezoelec- tric, pyroelectric and hybrid piezo- pyroelectric effects}

Three series of experiments were conducted in this study to investigate the coupling between piezoelectric and pyroelectric effects. Fig. 1 illustrates the material and experimental setup.

The PVDF sample measured as 1 inch by 1 inch (1 inch $=2.54 \mathrm{~cm})$ for the experiments was cut from commercially available PVDF film (Product 11004346-0, Measurement Specialties Inc., USA). The PVDF was originally produced from a meltingstretching-poling process. The process began with the melt extrusion of PVDF resin pellets into sheet form; the sheet was then mechanically stretched to reduce the sheet thickness to one-fifth. Stretching was performed at temperatures well below the melting point of the polymer, which caused chain packing of the molecules into parallel crystal planes, or the $\beta$ phase (Measurement Specialties Inc., 2013). 
The $\beta$ phase polymer was then exposed to very high electric fields to align the crystallites relative to the poling field (thickness direction) to enhance the piezoelectric activity (Measurement Specialties Inc., 2013). The manufacture values for the piezoelectric coefficient, pyroelectric coefficient, and the dielectric constant of the PVDF film can be found in Table 2. These values will be used in the modeling process later. Note that these parameters are not directly measured in this study since the main purpose is to test the hybrid piezo-pyroelectric effect, where the absolute values of these coefficients do not matter. Care was taken to remove the electrodes by the edges of the PVDF film to prevent electrical short circuit.

(a)

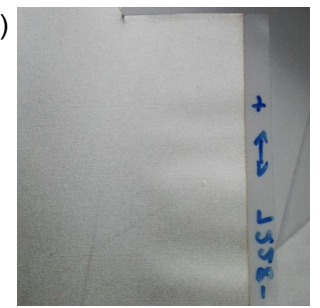

(c)

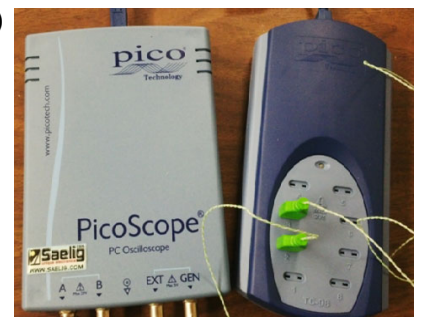

Fig. 1 Material and experimental setup

(a) PVDF film; (b) Hot plate and PVDF film; (c) PC oscilloscope and thermocouple

As discussed in the previous section, the mechanical and thermal boundary conditions will affect the measurement of pyroelectric effects. To reduce the secondary pyroelectric effect, the PVDF film was clamped to an aluminum beam which had much smaller thermal expansion coefficient; to reduce the tertiary pyroelectric effect, the aluminum beam was used as a heat conductor to avoid heating the sample directly. The PVDF film was bounded to one end of the aluminum beam, and an electrical insulation layer was added between the sample and the beam. The other end of the beam was fixed on a hot plate (Model 97042-690, VMR). The two electrodes of the PVDF sample were connected to a PC oscilloscope (Model 3204B, PICO ${ }^{\circledR}$ Technology) for voltage measurement. In addition, two thermocouples (PICO TC Probe, SE000) were bonded on the top and bottom surfaces of the PVDF sample to measure the temperature. The thermal signal was logged with a thermocouple data logger (TC-08, PICO $^{\mathbb{B}}$ Technology).

The detailed procedures for the three series of experiments are as follows:

1. To study the pure piezoelectric effect, the temperature conditions were kept constant when mechanical loading was applied with a weight of $31.7 \mathrm{~g}$. The weight was placed on top of the PVDF and then immediately withdrawn, inducing an impulse type of loading which is similar to the traffic loading but with a much smaller magnitude. From the oscilloscope output, the duration of the loading is about $0.7 \mathrm{~s}$. The loading tests were conducted at different temperature conditions (such as $35^{\circ} \mathrm{C}, 40^{\circ} \mathrm{C}$ and the like). These temperature conditions were controlled by a hot plate as shown in Fig. 1b. All the tests were conducted when the temperature was stabilized to eliminate possible pyroelectric effects. At each temperature, seven tests were conducted and the average piezoelectric effect induced voltage at different temperature conditions is shown in Fig. 2a.

2. To study the pure pyroelectric effect, the temperature of the PVDF sample was first heated to about $60{ }^{\circ} \mathrm{C}$ and then it was allowed to cool down freely to the room temperature of $30^{\circ} \mathrm{C}$ (Fig. 2b). No mechanical loading was applied. Seven tests were conducted and the average pyroelectric effect induced voltage is shown in Fig. 2c.

3. To study the coupled piezo-pyroelectric effect, the temperature of the PVDF sample was first heated to about $60{ }^{\circ} \mathrm{C}$. The same mechanical loading was repetitively applied as in Step 1, while the temperature gradually went down. Seven tests were conducted and the average of the generated voltage at the instances when the mechanical loading was applied is shown in Fig. 2d.

The output voltage of the PVDF film under different mechanical and thermal loadings is summarized in Fig. 2. Fig. 2a shows that the piezoelectric voltage under the same mechanical loading changes linearly with temperature. The increase of piezoelectric coefficient $d_{33}$ of PVDF with temperature (between the glass transition temperature $\left(-40{ }^{\circ} \mathrm{C}\right)$ and the breakdown of the piezoelectric film $\left.\left(80^{\circ} \mathrm{C}\right)\right)$ is a well-known phenomenon (Destruel et al., 1984; Guthner et al., 1992; Faust and Lakes, 2015). Note that this is independent of the pyroelectric effect. Pyroelectric effect only occurs when the temperature 

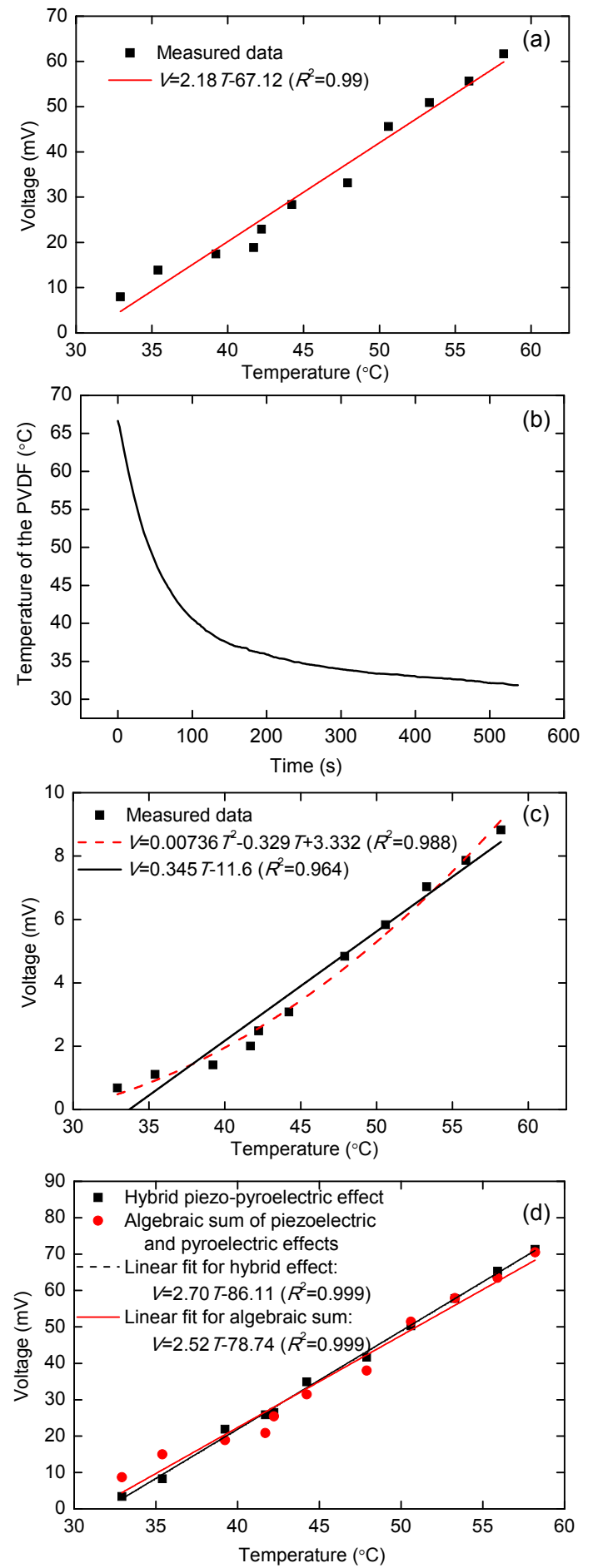

Fig. 2 Experimental results of pure piezoelectric effect (a), temperature profile (b), pure pyroelectric effect (c), and hybrid piezo-pyroelectric (d)

is fluctuating. However, the pure piezoelectric effects were tested under constant temperature. Several different mechanisms may contribute to this phenomenon. First, the higher temperature will cause a decrease of the stiffness of the polymer and therefore larger deformation will result from a same loading (Destruel et al., 1984; Guthner et al., 1992); a recent study indicated that the change of stiffness is not the only reason and their analysis indicates that flexoelectric effect may also play a role, especially when the PVDF is mounted on a non-polymer material such as aluminum used in this study (Faust and Lakes, 2015). The thermal stress on the voltage was included in the entire voltage. Since all the experiments were conducted under the same conditions except the mechanical loading and temperature, the effect from thermal stress is beyond the scope of this study and will not affect the validity of the conclusions which are mainly on the hybrid piezopyroelectric effects.

With decreasing temperature (Fig. 2b), the transient pyroelectric voltage also decreases (Fig. 2c). Note that if the temperature is decreased at a constant rate, from Eq. (3), the pyroelectric current and voltage should be constant. With the temperature profile shown in Fig. 2b, the decreasing rate (slope of the temperature curve) is decreasing. Therefore, the pyroelectric current and voltage are decreasing. The latter is shown in Fig. 2c.

Fig. 2d illustrates that the hybrid piezopyroelectric effect is close to the algebraic sum of the pure piezoelectric effect and the pure pyroelectric effect, indicating that when the two effects are coupled no strengthening or weakening effects will occur. Therefore, the total charges induced by the hybrid effect can be expressed as

$$
Q=Q_{\mathrm{T}}+Q_{\mathrm{M}},
$$

where $Q, Q_{\mathrm{T}}$, and $Q_{\mathrm{M}}$ are the total charges induced by the hybrid effect, the pure pyroelectric effect, and the pure piezoelectric effect, respectively.

\section{Modeling of the harvested energy consid- ering the hybrid piezo-pyroelectric effects}

\subsection{Harvesting circuit}

The PVDF energy harvester can be modeled as a current source with internal impedance (internal capacitance $C_{\mathrm{p}}$ and internal resistance $R_{\mathrm{p}}$ ) and the energy will be stored in an external capacitor $C_{\mathrm{E}}$ and will be consumed by the external loading $R_{\mathrm{E}}$ (Fig. 3). 
Since the harvester will experience both cooling and heating processes, the direction of $I_{\mathrm{p}}$ will change. Therefore, a full bridge with a four-diode rectifier is used to ensure that the charges will flow to $C_{\mathrm{E}}$ in the same direction. The capacitance of the PVDF harvester can be calculated using parallel plate theory, $C_{\mathrm{P}}=\frac{\varepsilon_{0} \varepsilon_{\mathrm{r}} A_{\mathrm{PVDF}}}{h}$, where $\varepsilon_{0}$ is the permittivity of a vacuum, $\varepsilon_{\mathrm{r}}$ is permittivity of PVDF, $A_{\mathrm{PVDF}}$ is the electrode area, and $h$ is the thickness of PVDF. The internal resistance is typically very large, and it can be assumed that no internal leakage will occur. To further simplify the modeling, it is assumed the diodes are ideal and no dissipation of energy occurs due to rectification. The external capacitance is usually large enough so that most of the charges will be harvested. In the following sections, the charge, voltage, and energy stored in $C_{\mathrm{E}}$ are modeled.

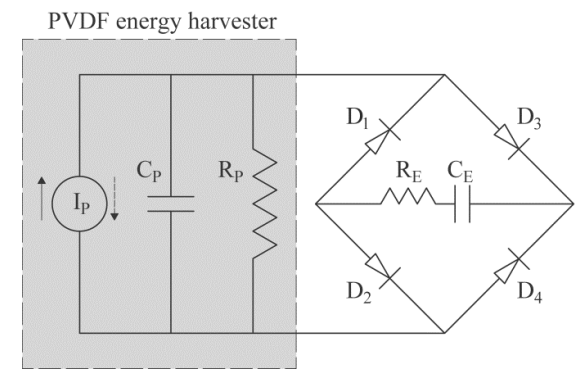

Fig. 3 Standard circuit for energy harvesting (modified from (Batra et al., 2011))

$C_{\mathrm{p}}$ and $R_{\mathrm{p}}$ are the capacitance and resistance of the clamped PVDF harvester, respectively, and $C_{\mathrm{E}}$ and $R_{\mathrm{E}}$ are the external capacitance and resistance, respectively. $D_{1}, D_{2}, D_{3}$, and $D_{4}$ are diodes, which are used to rectify current direction

\subsection{Pyroelectric effect induced charge, voltage, and energy}

Soedjatmiko et al. (1999) verified that pavement temperature varies with time and depth. During a day, temperatures typically reach the lowest in the middle night and the highest after midday. At a certain depth below the pavement (at a depth of $1.5 \mathrm{~m}$ in Ohio), the temperature remains constant $\left(15^{\circ} \mathrm{C}\right.$ in Ohio). At the pavement surface, the temperatures are the highest in the summer but the lowest in the winter. At the current stage, we simply assume that the PVDF film is embedded just beneath the wearing layer, and its temperature is assumed to be approximately the same as the pavement surface temperature.

The pyroelectric effect induced charges can be calculated by

$$
Q_{\mathrm{T}}=\rho \Delta T A_{\mathrm{PVDF}},
$$

where $\Delta T$ is the temperature change and $A_{\mathrm{PVDF}}$ is the surface area of the harvester electrode. Assuming that during one cycle of cooling or heating process, the pyroelectric effect-induced charge is $Q_{\mathrm{T}}$. In a random $n$th cycle, the charge is distributed between the internal and external capacitors (Cuadras et al., 2010), which is expressed as

$$
\Delta Q+Q_{\mathrm{P}}(n-1)+Q_{\mathrm{E}}(n-1)=Q_{\mathrm{P}}(n)+Q_{\mathrm{E}}(n),
$$

where $\Delta Q$ is the charge induced in the $n$th cycle; $Q_{\mathrm{P}}$ and $Q_{\mathrm{E}}$ are the charges stored in the external capacitor $\left(C_{\mathrm{E}}\right)$ and the internal capacitor $\left(C_{\mathrm{p}}\right)$, respectively. Typically, $C_{\mathrm{E}} \gg C_{\mathrm{p}}$.

$$
\begin{aligned}
& Q_{\mathrm{P}}(n)=V(n) C_{\mathrm{P}}, \\
& Q_{\mathrm{E}}(n)=V(n) C_{\mathrm{E}}, \\
& Q_{\mathrm{P}}(n-1)= \pm V(n-1) C_{\mathrm{P}}, \\
& Q_{\mathrm{E}}(n-1)=V(n-1) C_{\mathrm{E}},
\end{aligned}
$$

where $V$ is the voltage across $C_{\mathrm{E}}$. Note that the sign in the third term in the left hand side of Eq. (6) depends on the sign of temperature change $\Delta T$. That is, if both the $n$th and $(n-1)$ th cycles are cooling or heating processes, the current generated will be in the same direction; however, if the $n$th cycle is cooling (heating) while the $(n-1)$ th cycle is heating (cooling), the current generated in these two cycles will be opposite, and a negative sign will be used.

By substituting Eq. (7) into Eq. (6), we obtain the following equation (Cuadras et al., 2010; Batra et al., 2011):

$$
\begin{aligned}
V_{n} & =\frac{Q}{C_{\mathrm{E}}+C_{\mathrm{P}}}+\left(\frac{C_{\mathrm{E}} \pm C_{\mathrm{P}}}{C_{\mathrm{E}}+C_{\mathrm{P}}}\right) V_{n-1} \\
& =\frac{\rho A_{\mathrm{PVDF}} \Delta T}{C_{\mathrm{E}}+C_{\mathrm{P}}}+\left(\frac{C_{\mathrm{E}} \pm C_{\mathrm{P}}}{C_{\mathrm{E}}+C_{\mathrm{P}}}\right) V_{n-1} .
\end{aligned}
$$

Assume $V_{1}=0$ and with $C_{\mathrm{E}} \gg C_{\mathrm{p}}$, Eq. (8) reduces to

$$
V_{n}=\frac{\rho A_{\mathrm{PVDF}} \Sigma|\Delta T|}{C_{\mathrm{E}}+C_{\mathrm{P}}}=\frac{Q_{n}}{C_{\mathrm{E}}+C_{\mathrm{P}}},
$$


where $Q_{n}$ is the accumulated charges on $C_{\mathrm{E}}$ after the $n$th thermal cycle. The energy stored in CE is thus

$$
E_{n}=\frac{1}{2} C_{\mathrm{E}}\left(\frac{\rho A_{\mathrm{PVDF}} \Sigma|\Delta T|}{C_{\mathrm{E}}+C_{\mathrm{P}}}\right)^{2} .
$$

\subsection{Piezoelectric effect induced charge, voltage, and energy}

Considering that vehicles change lanes on a roadway, the PVDF harvester must be designed to cover the full lane width. The width of the harvester can be determined considering the length of the contact patches of the tires. The tire contact area can be assumed as a circular shape with a radius which can be determined by $r=\sqrt{F_{\text {wheel }} /\left(\pi p_{\text {tire }}\right)}$ (Huang, 1993), where $F_{\text {wheel }}$ is the axial wheel load of vehicle, $p_{\text {tire }}$ is the tire pressure, and $r$ is the contact radius. It is assumed that the width of the PVDF harvester is $2 r$.

Assuming that the harvester is embedded at depth $z$, the stress at this depth can be expressed as follows (Huang, 1993):

$$
\sigma_{z}=p_{\text {cont }}\left[1-\frac{z^{3}}{\left(r^{2}+z^{2}\right)^{1.5}}\right]
$$

where $\sigma_{z}$ is the stress at the depth of $z$, and $p_{\text {cont }}$ is the contact pressure, which can be assumed to be equal to $p_{\text {tire. }}$

Therefore, the piezoelectric effect-induced charge when a single tire passes the harvester is $Q_{\mathrm{M}}=d_{33} \sigma_{z} A_{\text {cont }}$.

Assuming that all the vehicles are two-axle vehicles and the traffic volume is $N$ per day, the charges induced by the vehicles in a single day will be

$$
Q_{\mathrm{M} \_ \text {day }}=4 N d_{33} \sigma_{z} A_{\text {cont }} \text {. }
$$

Substituting Eqs. (9) and (12) into Eq. (4), the total charges induced by the hybrid piezopyroelectric effect in a day is

$$
\begin{aligned}
Q_{\text {day }} & =Q_{\mathrm{T}_{-} \text {day }}+Q_{\mathrm{M}_{\_} \text {day }} \\
& =\rho A_{\mathrm{PVDF}} \sum_{\text {day }}|\Delta T|+4 N d_{33} \sigma_{z} A_{\text {cont }} .
\end{aligned}
$$

Similar to Eqs. (9) and (10), the voltage and energy can be calculated.

\section{Case study and discussion}

A typical pavement section in Wooster, Ohio is selected for the case study. This section is selected because both the air temperature and traffic data are available. The traffic data are summarized in Table 1 and the temperature record in 2014 is shown in Fig. 4a.

The harvester is designed to have a length of $3.7 \mathrm{~m}$ and a width of $24 \mathrm{~cm}$. Other parameters used

\begin{tabular}{|c|c|c|}
\hline Parameter & Value & Reference \\
\hline$C_{\mathrm{E}}(\mathrm{F})$ & $1 \times 10^{-3}$ & $\mathrm{n} / \mathrm{a}$ \\
\hline$A\left(\mathrm{~m}^{2}\right)$ & 0.888 & $\mathrm{n} / \mathrm{a}$ \\
\hline $\begin{array}{c}\rho \\
\left(\mu \mathrm{C} /\left(\mathrm{m}^{2} \cdot \mathrm{K}\right)\right)\end{array}$ & 30 & $\begin{array}{l}\text { Measurement Special- } \\
\text { ties Inc. }(2013)\end{array}$ \\
\hline$d_{33}(\mathrm{nC} / \mathrm{N})$ & 33 & $\begin{array}{l}\text { Measurement Special- } \\
\text { ties Inc. (2013) }\end{array}$ \\
\hline$h(\mu \mathrm{m})$ & 28 & $\begin{array}{l}\text { Measurement Special- } \\
\text { ties Inc. (2013) }\end{array}$ \\
\hline$\varepsilon_{\mathrm{r}}$ & 12.5 & $\begin{array}{l}\text { Measurement Special- } \\
\text { ties Inc. (2013) }\end{array}$ \\
\hline$\varepsilon_{0}(\mathrm{nF} / \mathrm{m})$ & 8.82 & $\mathrm{n} / \mathrm{a}$ \\
\hline$C_{\mathrm{P}}(\mu \mathrm{F})$ & 3.50 & $\mathrm{n} / \mathrm{a}$ \\
\hline
\end{tabular}
in the calculations are summarized in Table 2.

Table 1 Parameters of trucks and cars

\begin{tabular}{ccccc}
\hline $\begin{array}{c}\text { Vehicle } \\
\text { type }\end{array}$ & $\begin{array}{c}\text { Wheel load Tire pres- } \\
(\mathrm{kN})\end{array}$ & $\begin{array}{c}\text { Contact } \\
\text { sure }(\mathrm{kPa}) \\
\text { radius }(\mathrm{cm})\end{array}$ & $\begin{array}{c}\text { Traffic vol- } \\
\text { ume }\left(\mathrm{d}^{-1}\right)\end{array}$ \\
\hline Car & 4.79 & 220 & 8.25 & 26290 \\
Truck & 25 & 550 & 12 & 4000 \\
\hline Reference & Tao et al. & AASHTO & Huang & ODOT \\
& $(2014)$ & $(1993)$ & $(1993)$ & $(2015)$ \\
\hline
\end{tabular}

Table 2 Parameters of circuit components

Note: " $\mathrm{n} / \mathrm{a}$ " indicates that the reference is not available

Based on Eq. (1) and the available weather and traffic data, the accumulated charges due to the pyroelectric and piezoelectric effects during one year are plotted in Fig. 4b. It is clear that the piezoelectric charge is significantly larger than the pyroelectric charge. However, it should be noted that the temperature we used is the air temperature, which is different from the pavement surface temperature. However, the data for the latter are not currently available. Fig. $4 c$ shows the differences between the air temperature and asphalt concrete (AC) pavement surface temperature in a typical summer day in Cleveland, Ohio. It can be concluded that during the daytime, the pavement surface temperature is significantly higher than the air temperature, while late at night, the pavement surface can be cooler than the air. Fig. 4d illustrates the differences between the 

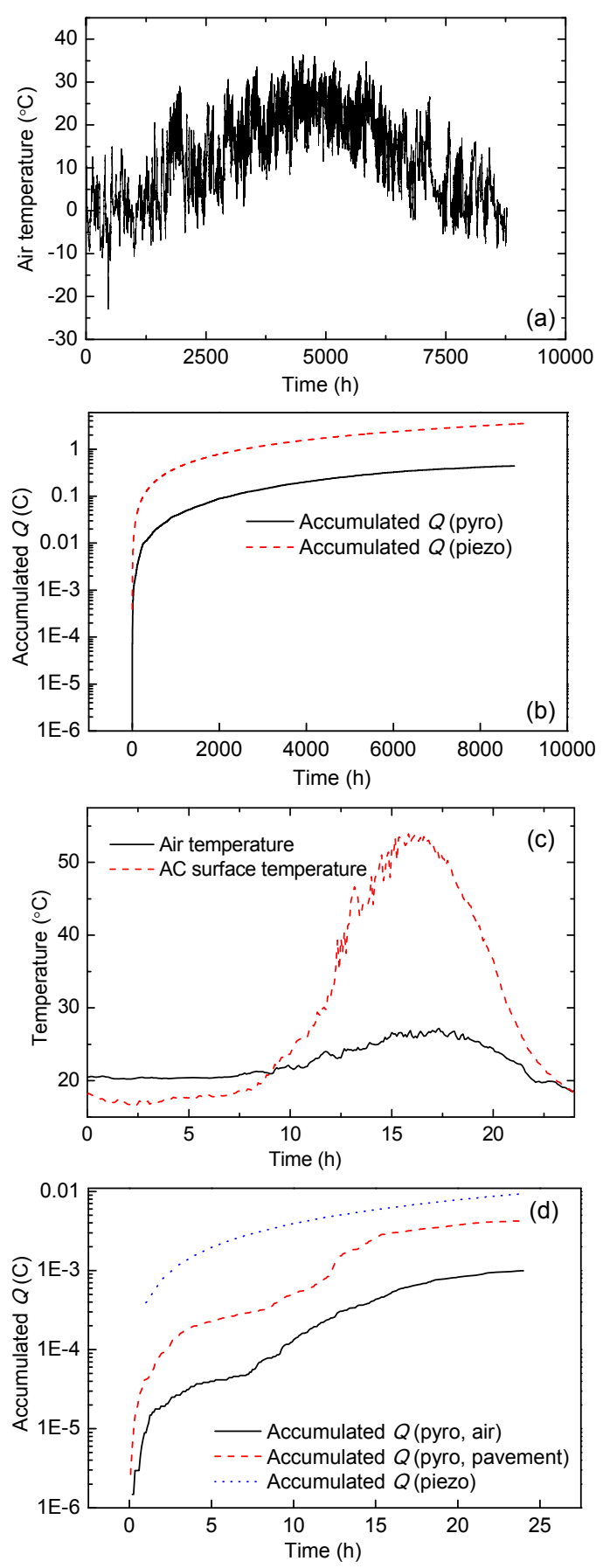

Fig. 4 (a) Temperature record in Wooster, Ohio, in 2014; (b) Comparison of piezoelectric and pyroelectric charges accumulated in one year; (c) Comparison of air temperature and pavement temperature in a summer day in Cleveland, Ohio; and (d) Comparison of pyroelectric charges calculated using air temperature and pavement temperature

pyroelectric charges calculated using both the air temperature and the pavement surface temperature. It can be concluded that if the pavement surface tem- perature is used, the pyroelectric charge becomes closer to the piezoelectric charges. This means that the pyroelectric effect cannot be neglected when using PVDF as a pavement energy harvester.

To better harvest the ambient thermal and mechanical energy, it is a straightforward approach to use materials with higher piezoelectric and pyroelectric constants. PZT is another commonly used piezoelectric material that has much larger piezoelectric and pyroelectric constants. However, the fragile nature of the material might affect its service life in the harsh pavement environment. As discussed in Section 1, PVDF nanocomposites provide another viable alternative to improve the energy harvesting potential. Table 3 summarizes the properties of recently developed PVDF nanocomposites. These properties are used for calculating the daily average accumulated charge, voltage, and energy.

From Table 3, it can be concluded that the use of PZT results in much higher energy than other materials, despite its fragile nature. For pure PVDF, PVDF-TrFE, and PZT 5H, the piezoelectric charges are much larger than the pyroelectric charges. For PVDF composites such as PVDF-TrFE/PZT and PVDF-TrFE/CNT, the pyroelectric effect outplaces the piezoelectric effect. PVDF-TrFE/CNT also results in the second highest accumulated charge. The energy stored in a day is more than sufficient to power commonly used wireless sensor nodes and even light-emitting diode lights.

\section{Conclusions and future work}

In this paper, the concept of energy harvesting from a pavement with hybrid piezo-pyroelectric effects is discussed. Laboratory experiments were conducted to study the hybrid effect, and it was found that the hybrid effect is equivalent to the algebraic sum of the individual piezoelectric and pyroelectric effects and no coupling effect (mutual strengthening or mutual weakening) is detected. Analytical models are developed to estimate the charge, voltage, and energy harvested considering the weather and traffic data. With such models, case studies are conducted to illustrate the feasibility of the concept. It is concluded that pyroelectric effect cannot be neglected when modeling the energy harvesting capacity of ferroelectric materials when used in pavement systems. It is also found that other materials such as PZT and PVDF nanocomposites can generate more 
Table 3 Comparison of properties of different ferroelectric materials and corresponding energy harvesting capacities

\begin{tabular}{|c|c|c|c|c|c|c|c|c|c|}
\hline Material & $\begin{array}{c}\rho \\
\left(\mu \mathrm{C} /\left(\mathrm{m}^{2} \cdot \mathrm{K}\right)\right)\end{array}$ & $\begin{array}{c}d_{33} \\
(\mathrm{pC} / \mathrm{N})\end{array}$ & $\varepsilon_{\mathrm{r}}$ & $\begin{array}{l}Q_{\text {Pyro }} \\
(\mathrm{mC})\end{array}$ & $\begin{array}{l}Q_{\text {Piezo }} \\
(\mathrm{mC})\end{array}$ & $\begin{array}{l}Q_{\mathrm{Hyb}} \\
(\mathrm{mC})\end{array}$ & $\begin{array}{l}V_{\mathrm{Hyb}} \\
(\mathrm{V})\end{array}$ & $\begin{array}{l}E_{\mathrm{Hyb}} \\
(\mathrm{mJ})\end{array}$ & Reference \\
\hline PVDF & 30 & 33 & 12.5 & 1.20 & 9.40 & 10.6 & 10.6 & 55.8 & $\begin{array}{l}\text { Measurement Specialties Inc. } \\
\text { (2013) }\end{array}$ \\
\hline PVDF-TrFE & 40 & 38 & 7.5 & 1.60 & 10.8 & 12.4 & 12.3 & 75.6 & $\begin{array}{l}\text { Measurement Specialties Inc. } \\
\text { (2013) }\end{array}$ \\
\hline PZT 5H & 400 & 593 & 3400 & 16.0 & 169 & 185 & 94.8 & 44900 & Vaish et al. (2015) \\
\hline TGS & 230 & 23 & 36.6 & 9.19 & 6.55 & 15.7 & 15.6 & 121 & $\begin{array}{l}\text { Banan et al. (1992); Xiong } \\
\quad \text { (2013) }\end{array}$ \\
\hline $\begin{array}{l}\text { PVDF-TrFE } \\
\quad / \text { PZT }\end{array}$ & 79 & 10 & 45 & 3.16 & 2.85 & 6.01 & 5.93 & 17.6 & Dietze and Es-Souni (2008) \\
\hline $\begin{array}{l}\text { PVDF-TrFE } \\
\text { /CNT }\end{array}$ & 63.9 & 44.8 & 26.17 & 25.5 & 12.8 & 38.3 & 38.0 & 723 & Levi et al. (2004) \\
\hline $\begin{array}{l}\text { PVDF-TrFE } \\
\quad / \mathrm{rGO}\end{array}$ & 27.4 & 76 & 7.5 & 10.8 & 21.6 & 32.4 & 32.4 & 524 & $\begin{array}{l}\text { Hu et al. (2014); Alamusi et } \\
\quad \text { al. (2012) }\end{array}$ \\
\hline
\end{tabular}

$Q_{\text {Pyro }}, Q_{\text {Piezo }}$, and $Q_{\mathrm{Hyb}}$ denote the charges induced by pure pyroelectric effect, pure piezoelectric effect, and pure hybrid effect, respectively. $V_{\mathrm{Hyb}}$ and $E_{\mathrm{Hyb}}$ denote the hybrid accumulated voltage and energy, respectively. TGS: triglycine sulphate

energy than pure PVDF materials. While PZT is fragile and may not be used directly in a pavement system, PVDF-TrFE/CNT nanocomposites are viable alternative materials that can better harness both the thermal and mechanical energy wasted in pavement systems. Ongoing efforts include synthesizing new materials which will enhance the piezoelectric and pyroelectric conversion efficiency of ferroelectric materials and optimizing the geometry and distribution of the energy harvester. Experiments are also being conducted to further validate the analytical model developed in this paper.

\section{References}

AASHTO (American Association of State Highway and Transportation Officials), 1993. AASHTO Guide for Design of Pavement Structures. AASHTO, USA.

Alamusi, Xue, J.M., Wu, L.K., et al., 2012. Evaluation of piezoelectric property of reduced graphene oxide (rGO)poly (vinylidene fluoride) nanocomposites. Nanoscale, 4(22):7250-7255. http://dx.doi.org/10.1039/c2nr32185h

Banan, M., Lal, R.B., Batra, A., 1992. Modified triglycine sulphate (TGS) single crystals for pyroelectric infrared detector applications. Journal of Materials Science, 27(9):2291-2297.

http://dx.doi.org/10.1007/BF01105034

Batra, A.K., Bhattacharjee, S., Chilvery, A.K., et al., 2011. Simulation of energy harvesting from roads via pyroelectricity. Journal of Photonics for Energy, 1(1):014001. http://dx.doi.org/10.1117/1.3656395

Bowen, C.R., Taylor, J., Leboulbar, E., et al., 2014. Pyroelectric materials and devices for energy harvesting applications. Energy \& Environmental Science, 7(12):3836-3856. http://dx.doi.org/10.1039/C4EE01759E
Chen, K.S., 2014. Design, analysis, and experimental studies of a novel PVDF-based piezoelectric energy harvester with beating mechanisms. ASME International Mechanical Engineering Congress and Exposition, American Society of Mechanical Engineers, Montreal, Quebec, Canada, No. IMECE2014-36968. http://dx.doi.org/10.1115/IMECE2014-36968

Cuadras, A., Gasulla, M., Ferrari, V., 2010. Thermal energy harvesting through pyroelectricity. Sensors and Actuators A: Physical, 158(1):132-139. http://dx.doi.org/10.1016/j.sna.2009.12.018

Destruel, P., Soto Rojas, F., Tougne, D., 1984. Pressure and temperature dependence of the electromechanical properties of polarized polyvinylidene fluoride films. Journal of Applied Physics, 56(11):3298-3303. http://dx.doi.org/10.1063/1.333851

Dietze, M., Es-Souni, M., 2008. Structural and functional properties of screen-printed PZT-PVDF-TrFE composites. Sensors and Actuators A: Physical, 143(2):329334. http://dx.doi.org/10.1016/j.sna.2007.11.016

Faust, D., Lakes, R., 2015. Temperature and substrate dependence of piezoelectric sensitivity for PVDF films. Ferroelectrics, 481(1):1-9. http://dx.doi.org/10.1080/00150193.2015.1048149

Guthner, P., Ritter, T., Dransfeld, K., 1992. Temperature dependence of the piezoelectric constant of thin PVDF and P(VDF-TrFE) films. Ferroelectrics, 127:7-11.

Guan, X., Zhang, Y., Li, H., et al., 2013. PZT/PVDF composites doped with carbon nanotubes. Sensors and Actuators A: Physical, 194:228-231. http://dx.doi.org/10.1016/j.sna.2013.02.005

Hill, D., Agarwal, A., Tong, N., 2014. Assessment of Piezoelectric Materials for Roadway Energy Harvesting: Cost of Energy and Demonstration Roadmap. California Energy Commission Energy Research and Development Division Final Project Report, No. Cec-500-2013-007. 
Hu, Y., Hsu, W., Wang, Y., et al., 2014. Enhance the pyroelectricity of polyvinylidene fluoride by graphene-oxide doping. Sensors, 14(4):6877-6890. http://dx.doi.org/10.3390/s140406877

Huang, L., Lu, C., Wang, F., et al., 2014. Preparation of PVDF/graphene ferroelectric composite films by in situ reduction with hydrobromic acids and their properties. RSC Advances, 4(85):45220-45229. http://dx.doi.org/10.1039/C4RA07379G

Huang, Y.H., 2003. Pavement Analysis and Design, 2nd Edition. Pearson, Upper Saddle River, New Jersey, USA, p.45-90

Kim, G.H., Hong, S.M., Seo, Y., 2009. Piezoelectric properties of poly (vinylidene fluoride) and carbon nanotube blends: $\beta$-phase development. Physical Chemistry Chemical Physics, 11(44):10506-10512. http://dx.doi.org/10.1039/b912801h

Levi, N., Czerw, R., Xing, S., et al., 2004. Properties of polyvinylidene difluoride-carbon nanotube blends. Nano Letters, 4(7):1267-1271. http://dx.doi.org/10.1021/n10494203

Li, X., Lu, S., Chen, X., et al., 2013. Pyroelectric and electrocaloric materials. Journal of Materials Chemistry $C$, 1(1):23-37. http://dx.doi.org/10.1039/C2TC00283C

Luo, B., Wang, X., Wang, Y., et al., 2014. Fabrication, characterization, properties and theoretical analysis of ceramic/PVDF composite flexible films with high dielectric constant and low dielectric loss. Journal of Materials Chemistry A, 2(2):510-519. http://dx.doi.org/10.1039/C3TA14107A

Malmonge, L.F., Malmonge, J.A., Sakamoto, W.K., 2003. Study of pyroelectric activity of PZT/PVDF-HFP composite. Materials Research, 6(4):469-473. http://dx.doi.org/10.1590/S1516-14392003000400007

Measurement Specialties Inc., 2013. Piezo Film Sensors Technical Manual. Available from http://www.measspec.com [Accessed in April, 2014].

ODOT (Ohio Department of Transportation), 2015. Traffic Survey Report. Available from http://www.dot.state. oh.us/Divisions/Planning/TechServ/traffic/Pages/TrafficCount-Reports-and-Maps.aspx [Accessed on July 2015].

Rahman, M.A., Chung, G.S., 2013. Synthesis of PVDFgraphene nanocomposites and their properties. Journal of Alloys and Compounds, 581:724-730.

Soedjatmiko, E., 1999. Characterization of Asphalt Layer Modulus for Indonesian Temperature Condition. MS Thesis, Institut Teknologi Bandung, Indonesia.

Thomas, P., Varughese, K., Dwarakanath, K., et al., 2010. Dielectric properties of poly (vinylidene fluoride)/ $\mathrm{CaCu}_{3} \mathrm{Ti}_{4} \mathrm{O}_{12}$ composites. Composites Science and Technology, 70(3):539-545.

http://dx.doi.org/10.1016/j.compscitech.2009.12.014

Ueberschlag, P., 2001. PVDF piezoelectric polymer. Sensor Review, 21(2):118-126. http://dx.doi.org/10.1108/02602280110388315

Vaish, M., Sharma, M., Vaish, R., et al., 2015. Experimental study on waste heat energy harvesting using lead zir- conate titanate $(\mathrm{PZT}-5 \mathrm{H})$ pyroelectric ceramics. Energy Technology, 3(7):768-773.

http://dx.doi.org/10.1002/ente.201500050

Xiong, H., Wang, L., Wang, D., et al., 2012. Piezoelectric energy harvesting from traffic induced deformation of pavements. International Journal of Pavement Research and Technology, 5(5):333-337.

http://dx.doi.org/10.6135\%2fijprt.org.tw\%2f2012.5(5).333

Xiong, R.G., 2013. The temperature-dependent domains, SHG effect and piezoelectric coefficient of TGS. Chinese Chemical Letters, 24:681-684.

http://dx.doi.org/10.1016/j.cclet.2013.05.015

Zhang, R., Jiang, B., Cao, W., 2001. Elastic, piezoelectric, and dielectric properties of multidomain $0.67 \mathrm{~Pb}\left(\mathrm{Mg}_{1 / 3} \mathrm{Nb}_{2 / 3}\right) \mathrm{O}_{3}-0.33 \mathrm{PbTiO}_{3}$ single crystals. Journal of Applied Physics, 90(7):3471-3475. http://dx.doi.org/10.1063/1.1390494

Zhao, H., Yu, J., Ling, J., 2010. Finite element analysis of cymbal piezoelectric transducers for harvesting energy from asphalt pavement. Journal of the Ceramic Society of Japan, 118(1382):909-915.

http://dx.doi.org/10.2109/jcersj2.118.909

Zhao, H., Tao, Y., Niu, Y., et al., 2014. Harvesting energy from asphalt pavement by piezoelectric generator. Journal of Wuhan University of Technology-Material Science Education, 29(5):933-937. http://dx.doi.org/10.1007/s11595-014-1023-3

\section{中文概要}

\section{题 目: 路面能量收集: 聚偏氟乙烯的混合压电-热释电} 效应

目 的: 研究聚偏氟乙烯的混合压电-热释电效应; 评估 混合压电-热释电效应在路面能量收集中的 潜力。

创新点: 首次实验验证了混合压电-热释电效应可视为压 电效应和热释电效应的代数总和, 即压电效应 和热释电效应相对独立, 既不相互压制也不相 互促进。

方 法: 通过分别控制机械荷载和热荷载, 实验测定聚 偏氟乙烯压电效应、热释电效应及混合压电-热 释电效应（图 1 和 2); 根据实地交通量和气温 变化, 通过简化的混合压电-热释电能量收集解 析模型, 估算美国俄亥俄州东北部地区路面能 量收集的潜力（图 4）。

结 论：混合压电-热释电效应可视为压电效应和热释电 效应的代数总和; 在聚偏氟乙烯路面能量收集的 建模中应该同时考虑压电效应和热释电效应; 以 本文中所选地区和材料为例, 热释电效应弱于压 电效应; 混合压电-热释电效应能量收集效率的 提高有望通过新型的纳米复合材料实现。

关键词：压电; 热释电; 混合; 路面; 能量收集 